\title{
STUDI PEMBUATAN SUDU KINCIR SAVONIUS BERSIRIP SUMBU VERTIKAL UNTUK PEMBANGKIT LISTRIK TENAGA BAYU (PLTB)
}

\author{
Suyanta, Etik Puspitasari \\ Jurusan Teknik Mesin, Politeknik Negeri Malang \\ email: s.suyanta@polinema.ac.id
}

(Artikel diterima: Februari 2020, direvisi: April 2020, diterima untuk terbit: Juli 2020)

\begin{abstract}
Abstrak - Pemanfaatan angin/bayu digunakan sebagai penggerak kincir dalam membuat energi listrik lebih dahulu diubah ke dalam energi mekanik putaran kemudian sebagai pembangkit listrik untuk menggerakkan generator. Untuk keperluan tersebut dibutuhkan kincir yang dapat menangkap energi angin dan diharapkan mempunyai efiensi besar, sehingga hambatan yang ditimbulkan dapat ditekan sekecil mungkin. Oleh karena itu pada penelitian ini dirancang suatu bentuk kincir savonius berporos vertikal dan bersirip, dibentuk bersirip diharapkan dapat mengurangi hambatan angin yang melawan putaran kincir. Konsep pembuatan prototipe kincir mengikuti bentuk dasar turbin savonius, yang sudu-sudunya terbagi menjadi 3 (tiga) buah sirip yang dilengkapi engsel, shingga gerak kincir angin lebih leluasa dibandingkan dengan kincir menggunakan sudu kincir tidak bersirip (rigid), diharapkan dengan konsep prototipe ini dapat menaikkan efisiensi daya yang dihasilkan.
\end{abstract}

Kata kunci: Sudu bersirip, kincir savonius, poros vertikal.

\section{Pendahuluan}

Kebutuhan energi listrik nasional terus meningkat mengikuti perkembangan kebutuhan penduduk dan kesejahteraan ekonomi masyarakat, semakin sejahtera semakin banyak menggunakan tenaga listrik dalam pemenuhan kegiatan sehari-hari. Perkembangan penelitian dalam bidang energi terbarukan khususnya tenaga angin (bayu) cukup banyak, dengan berbagai macam bentuk alat sebagai pesawat penangkap energi yang ditimbulkan oleh laju aliran angin.

Potensi angin di beberapa daerah tertentu cukup bermanfaat untuk dikelola menjadi sumber energi listrik yang signifikan, meskipun memerlukan biaya tinggi di awalnya. Dengan pengelolaan dan mempertimbangkan topografi dan demografi kependudukan sebagai dasar pemanfaatan energi angin. Misal pertimbangan jauh dari jangkauan linstrik PLN, karena infrastruktur jaringan mahal karena transmisi terlalu jauh, pulau terpencil.

Dalam usaha meningkatkan mutu kehidupan dan pertumbuhan ekonomi pedesaan, energi listrik memiliki peranan yang sangat penting. Ketersediaan energi listrik di pedesaan sebagai salah satu bentuk energi yang siap pakai, selain untuk penerangan tentu saja akan mendorong peningkatan sarana pendidikan, kesehatan dan keamanan lingkungan serta dapat meningkatkan penyediaan lapangan kerja baru.

Daerah pedesaan terpencil yang sebagian besar belum terjangkau jaringan Perusahaan Listrik Nasional (PLN) merupakan suatu masalah bagi pembangunan dan pengembangan masyarakat pedesaan. Kebutuhan energi masyarakat pedesaan terpencil untuk memasak, penerangan, dll umumnya berasal dari energi yang tidak dapat diperbaharui (seperti minyak). Adapun peralatan elektronik seperti radio, televisi dipenuhi dengan menggunakan baterai atau aki yang dalam jangka waktu tertentu harus diisi ulang (recharge). Pedalaman merupakan salah satu desa terpencil yang belum terjangkau oleh jaringan listrik PLN karena terletak di daerah dataran tinggi. Sehingga dengan memanfaatkan tenaga ngin tersebut diharapkan dapat memenuhi kebutuhan daya listrik.

Dengan demikian diharapkan dapat meningkatkan taraf hidup dan meningkatkan sumber daya masyarakat agar tidak tertinggal dengan daerah-daerah lain yang sudah dialiri jaringan listrik PLN.

Keadaan - keadaan diatas menjadi dasar bagi penulis untuk membahas studi potensi tenaga angin yang dapat dimanfaatkan untuk membangkitkan tenaga listrik serta perencanaan pembangunan Pembangkit Listrik Tenaga Bayu (PLTMB).

Tabel 1.1 Cadangan dan Produksi (Energi Non Fosil) Indonesia tahun 2007

\begin{tabular}{|l|l|l|l|}
\hline No. & $\begin{array}{l}\text { Energi Non } \\
\text { Fosil }\end{array}$ & Sumber Daya & $\begin{array}{l}\text { Kapasitas } \\
\text { Terpasang }\end{array}$ \\
\hline $\mathbf{1 .}$ & Tenaga Air & $\begin{array}{l}\mathbf{7 5 , 6 7} \text { GW (e.q. } \\
\mathbf{8 4 5} \text { juta SBM) }\end{array}$ & $\mathbf{4 , 2} \mathbf{~ G W}$ \\
\hline 2. & Panas Bumi & $\begin{array}{l}\text { 27 GW (e.q. } 219 \\
\text { juta SBM) }\end{array}$ & $0,8 \mathrm{GW}$ \\
\hline 3. & $\begin{array}{l}\text { Mini/micro } \\
\text { hydro }\end{array}$ & $0,45 \mathrm{GW}$ & $0,084 \mathrm{GW}$ \\
\hline 4. & Bio-mass & $49,81 \mathrm{GW}$ & $0,3 \mathrm{GW}$ \\
\hline 5. & Tenaga Surya & $4,8 \mathrm{kWh} / \mathrm{m} 2 /$ day & $0,008 \mathrm{GW}$ \\
\hline $\mathbf{6 .}$ & $\begin{array}{l}\text { Tenaga } \\
\text { angin }\end{array}$ & $\mathbf{9 , 2 9} \mathbf{G W}$ & $\mathbf{0 , 0 0 0 5} \mathbf{G W}$ \\
\hline 7. & $\begin{array}{l}\text { Uranium *) } \\
\end{array}$ & $\begin{array}{l}3 \mathrm{GW}(\text { e.q. } \\
24,112 \text { ton) untuk } \\
11 \text { tahun }\end{array}$ & $30 \mathrm{GW}$ \\
\hline
\end{tabular}

Sumber: www.esdm.go.id, Partowidagdo (2009: 400).

\section{KaJian PUSTAKa}

\section{A. Pemanfaatan Energi Angin}

Sistem konversi energi angin (SKEA) merupakan suatu sistem yang bertujuan untuk mengubah energi kinetik angin menjadi energi mekanik poros turbin untuk kemudian diubah lagi oleh generator menjadi energi listrik. Daya angin adalah energi yang dibangkitkan oleh gerak angin dengan kecepatan tertentu per satuan waktu, maka:

Energi Kinetik $=1 / 2 m v^{2}$ 
Beberapa formula/rumus yang digunakan di dalam perhitungan perancangan PLTB tipe baling-baling vertikal. Besar energi kinetis (E) yang dihasilkan dapat dihitung dengan rumus sbb.:

$$
\begin{array}{lc}
\multicolumn{1}{c}{\mathrm{E}=1 / 2 \mathrm{~m} \mathrm{~V}^{2}} & \text { [joule] } \\
\text { Dimana, } & {[\mathrm{joule}]} \\
\mathrm{E}=\text { Energi kinetis } & {[\mathrm{m} / \mathrm{s}]} \\
\mathrm{m}=\text { massa udara yang mengalir }[\mathrm{kg}] \\
\mathrm{V}=\text { kecepatan angin }
\end{array}
$$

Massa udara (m) yang mengalir dapat dihitung dengan rumus sbb.:

Dimana,

$$
\mathrm{m}=\rho \mathrm{AV} \quad[\mathrm{kg} / \mathrm{s}]
$$

$\rho=$ kerapatan udara

$\mathrm{A}=$ luas penampang PLTB

$\left[\mathrm{kg} / \mathrm{m}^{3}\right]$ $\left[\mathrm{m}^{2}\right]$

Besar energi yang dihasilkan per satuan waaktu (P) dapat dihitung dengan rumus sbb.:

$$
\mathrm{P}=1 / 2 \rho \mathrm{A} \mathrm{V}^{3} \quad[\text { watt }]
$$

Daya efektif $\left(E_{a}\right)$ yang dihasilkan oleh kincir angin Brown, CK dan Warne (1975) menyatakan bahwa daya efektif $\left(E_{a}\right)$ yang dihasilkan oleh kincir angin adalah sbb.:

$$
\mathrm{E}_{\mathrm{a}}=1 / 2 \rho \mathrm{c}_{\mathrm{P}} \mathrm{D}^{2} \mathrm{~V}^{3} \quad[\text { watt }]
$$

Dimana,

$\mathrm{c}_{\mathrm{P}}=$ koefisien daya

$\mathrm{D}=$ Diameter kincir angin $\quad[\mathrm{m}]$

Energi listrik yang dibangkitkan per satuan luas penampang sudu kincir angin adalah sbb.:

$$
(\text { Psystem } / \mathrm{A}) \mathrm{wP}_{\mathrm{P}}=1 / 2 \rho \times \mathrm{c}_{\mathrm{p}} \times \eta_{\mathrm{tr}} \times \eta_{\mathrm{g}} \times \mathrm{V}^{3} \quad\left[\mathrm{watt} / \mathrm{m}^{2}\right]
$$

Dimana,

$\eta_{\text {tr }}=$ Efisiensi transmisi

$\eta_{\mathrm{g}}=$ Efisiensi generator

Energi listrik yang dibangkitkan per satuan waktu adalah sbb.:

$$
(\mathrm{P} \text { system } / \mathrm{A})=0,1454 \mathrm{~V}^{3} \mathrm{dt} \quad\left[\mathrm{watt} / \mathrm{m}^{2}\right]
$$

Dimana,

$$
\mathrm{dt}=\text { Satuan waktu }
$$

[sekon]

\section{METODE}

Dengan melakukan modifikasi sudu pada kincir angin statik kemudian diubah menjadi beberapa sirip diharapkan dapat mengurang hambatan pada aliran angin yang melawan putaran kincir.

Pembuatan prototipe model kincir angin bersirip adalah, dengan jalan membagi sudu kincir menjadi tiga bagian sirip pada setiap sudu. Menurut penelitian kincir savonius sudu yang efektif 3 buah sudu. Berikut gambar sudu yang sudah dimodifikasi.

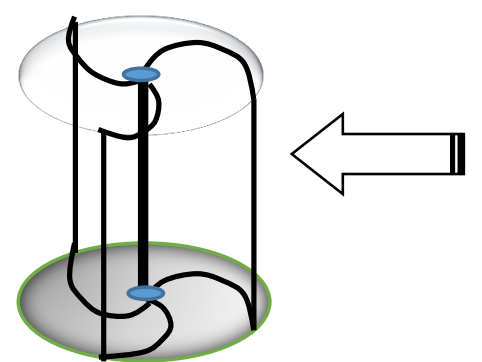

Gambar 3.1. Kincir sebelum dimodifikasi tanpa sirip. Sirip terbuka

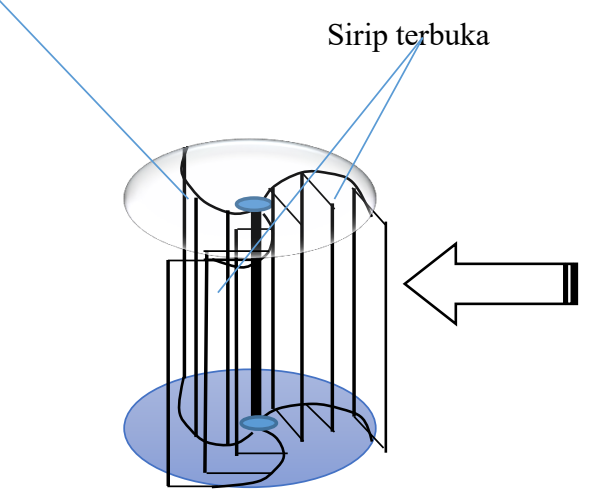

Gambar3.2 Kincir setelah dimodifikasi.

Modifikasi sirip dibuat agar sirip dapat bergerak ketika melawan tekanan angin pada posisi tertentu.

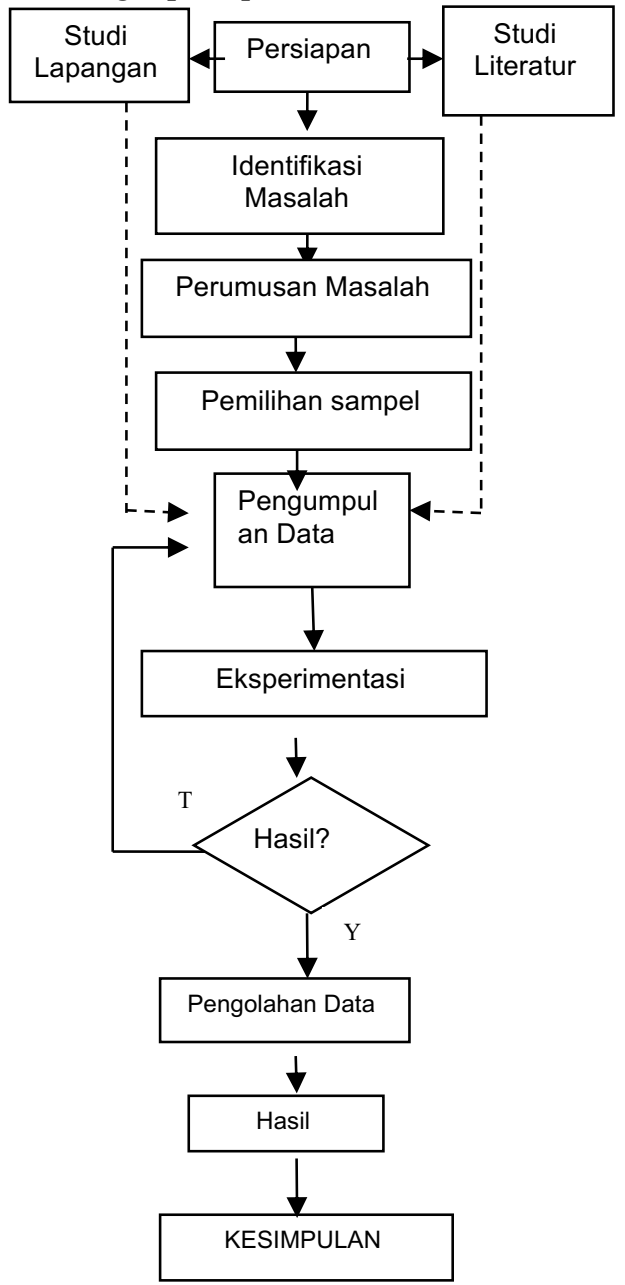

Gambar 3.3. Flow chart metodologi penelitian 


\section{Pembahasan}

Setelah dilakukan modifikasi pada sudu kincir angin kemudian dilaksanakan pengujian di lapangan dengan mengukur kecepatan putaranya diperoleh hasil pengamatan yang menunjukkan perbandingan seperti pada data sbb:

\begin{tabular}{|c|c|c|}
\hline No & $\begin{array}{c}\text { Kecepatan angin } \\
\text { untuk start sudu } \\
\text { tidak bersirip m/s }\end{array}$ & $\begin{array}{c}\text { Kecepatan angin } \\
\text { untuk start sudu } \\
\text { bersirip m/s }\end{array}$ \\
\hline 1 & 2,31 & 3,21 \\
\hline 2 & 2,33 & 3,22 \\
\hline 3 & 2,37 & 3,21 \\
\hline 4 & 2,31 & 3,23 \\
\hline 5 & 2,33 & 3,23 \\
\hline 6 & 2,38 & 3,26 \\
\hline 7 & 2,37 & 3,22 \\
\hline 8 & 2,36 & 3,82 \\
\hline 9 & 2,37 & 3,32 \\
\hline 10 & 2,35 & 3,72 \\
\hline 11 & 2,35 & 3,21 \\
\hline 12 & 2,35 & 3,52 \\
\hline 13 & 2,37 & 3,82 \\
\hline 14 & 2,31 & 3,22 \\
\hline 15 & 2,34 & 3,21 \\
\hline Rata-rata & 2,192666667 & 3,361333333 \\
\hline
\end{tabular}

\begin{tabular}{|c|c|c|}
\hline No & $\begin{array}{l}\text { Kecepatan angin } \\
\text { untuk start } \\
\text { sudu tidak } \\
\text { bersirip } \mathrm{m} / \mathrm{s}\end{array}$ & $\begin{array}{l}\text { Kecepatan angin } \\
\text { untuk start } \\
\text { sudu bersiirip } \mathrm{m} / \mathrm{s}\end{array}$ \\
\hline 1 & 2,01 & 3,21 \\
\hline 2 & 2,33 & 3,22 \\
\hline 3 & 2,77 & 3,21 \\
\hline 4 & 2,31 & 3,23 \\
\hline 5 & 2,33 & 3,23 \\
\hline 6 & 2,38 & 3,26 \\
\hline 7 & 2,37 & 3,22 \\
\hline 8 & 2,36 & 3,82 \\
\hline 9 & 2,37 & 3,32 \\
\hline 10 & 2,05 & 3,72 \\
\hline 11 & 2,35 & 3,21 \\
\hline 12 & 2,35 & 3,52 \\
\hline 13 & 2,52 & 3,82 \\
\hline 14 & 2,39 & 3,22 \\
\hline 15 & 2,54 & 3,21 \\
\hline Rata-rata & 2,228 & 3,1473333 \\
\hline
\end{tabular}

Dari pengamatan diperoleh gerakan sirip tidak dapat menutup sempurna, ada kecenderungan angin lolos/lewat , sehingga tidak menjadi menambah power bahkan akan terjadi pengurangan sebesar $40 \%$.

\section{KeSIMPULAN DAN SARAN}

\section{A. Kesimpulan}

Setelah dilakuka modifikasi dari bentuk sudu statis/rigid ke bentuk bersirip dinamis maka diperoleh hasil seperti grafik yang dapat dilihat pada gambar di depan, dengan kesimpulan bahwa telah terjadi perubahan penurunan daya sebesar $15 \%$.

\section{B. Saran-saran}

Agar perubahan yang dapat memberikan manfaat yang lebih riil perlu dilakukan pengkajian dan penelitian lanjut dengan memberikan perlakukuan dan modifikasi beberapan bentuk sudu yang berbeda.

\section{Daftar Pustaka}

[1] Kailash Golecha, T.I. Eldho, S.V. Prabhu. 2010. "Influence of The Deflector Plate on The Performance of Modified Savonius Water Turbine". Indian Institute of Technology, Bombay, India

[2] Burçin Deda Altan, Mehmet Atılgan, Aydog an Özdamar. 2007. "An experimental study on improvement of a Savonius rotor performance with curtaining". Department of Mechanical Engineering, Faculty of Engineering, Pamukkale University, Kınıklı 20070 Denizli, Turkey. Department of Mechanical Engineering, Faculty of Engineering, Ege University, Bornova, 35100 Izmir, Turkey.

[3] Saha UK, Thotla S, Maity D. "Optimum design configuration of Savonius rotor through wind tunnel experiments". J Wind Eng Ind Aerod 2008;96:1359-75.

[4] Ushiyama I, Nagai H. "Optimum design configurations and performance of Savonius rotors”. Wind Eng 1988;12:59-75. 